\title{
Independent Effects of Metabolic Syndrome and Air Pollution (PM2.5) on Atherosclerosis in Modernizing China
}

\author{
Woo KS ${ }^{1 *}$, Timothy KCY ${ }^{1}$, Chook $\mathrm{P}^{1,2}, \mathrm{Hu} \mathrm{YJ}^{3}$, \\ Yin $\mathrm{YH}^{4}$, Lin CQ ${ }^{5}$, Lau KHA ${ }^{5}$, Lee PWA ${ }^{1}$ and \\ Celermajer DS $^{6}$ \\ 'Department of Medicine and Therapeutics, The Chinese \\ University of Hong Kong, Hong Kong SAR \\ ${ }^{2}$ Institute of Chinese Medicine, The Chinese University of \\ Hong Kong, Hong Kong SAR \\ ${ }^{3}$ Nineth Peoples' Hospital of Chongqing, China \\ ${ }^{4}$ Second Hospital of Chongqing Medical University, China \\ ${ }^{5}$ Department of Civil and Environment and Engineering, \\ Hong Kong University of Science and Technology, Hong \\ Kong SAR \\ ${ }^{6}$ Faculty of Medical and Health Science, The University of \\ Sydney, Sydney, Australia \\ *Correspondling author: KS Woo, Department of \\ Medicine \& Therapeutics, Tsang Shiu Tim Building, \\ United College, The Chinese University of Hong Kong, \\ Shatin NT, Hong Kong SAR
}

Received: April 24, 2021; Accepted: May 13, 2021; Published: May 20, 2021

\begin{abstract}
Background: Air Pollution (AP) and metabolic syndrome (MS) are important global health hazards of the $21^{\text {st }}$ century, in mainland China in particular, and AP has been associated with increased prevalence of cardiovascular diseases, and stroke.

Methods: To evaluate the impact of metabolic syndrome on AP-related atherogenesis, 1557 Han Chinese adults (mean age 47.2 \pm 11.8 years, male $47 \%$ ) in Hong Kong, Macau, Pun Yu, Yu County (Shanxi coalmine) and 3-Gorges (Yangtze River) were studied. Cardiovascular risk profiles and metabolic syndrome (IDF criteria) were evaluated. PM2.5 (satellite sensor modeling), and atherosclerotic surrogates, brachial reactivity (FMD) and carotid Intima-media thickness (IMT) (ultrasound), were measured.
\end{abstract}

Results: The yearly PM2.5 concentration ranged from $34.0 \mu \mathrm{g} / \mathrm{m}^{3}$ in Hong Kong to $93.8 \mu \mathrm{g} / \mathrm{m}^{3}$ in 3-Gorges Territories. MS was diagnosed in 340 subjects (21.8\%). Smoking status, gender and PM2.5 were similar in the MS cohort versus those without MS. Blood pressures (SBP and DBP), waist circumference, triglycerides and glucose were higher, but high-density lipidcholesterol was lower in the MS cohort, compared to the other subjects. Brachial FMD was significantly lower and carotid IMT significantly higher $(0.70 \pm 0.13 \mathrm{~mm}$, $95 \% \mathrm{Cl} 0.68-0.71 \mathrm{~mm}$ vs. $0.63 \mathrm{~mm} \pm 0.14 \mathrm{~mm}, 95 \% \mathrm{Cl} 0.62-0.64 \mathrm{~mm}$ ) in the MS cohort than those without $(P<0.0001)$.

On multivariate regression, PM2.5 was not related to MS development, but was significantly related to carotid IMT in both no MS (beta=0.234, $P<0.0001$ ) and MS cohorts (beta $=0.245, p<0.0001$ ), independent of age, SBP, and waist circumference. There was no direct interaction between PM2.5 and MS.

Conclusions: Both AP and MS have independent impacts on atherogenic processes in China, with significant implications for atherosclerosis prevention.

Keywords: Flow-mediated dilation; Carotid intima-media thickness; Air pollution (PM2.5); Metabolic Syndrome; Modernizing China

\section{Abbreviations}

AP: Air Pollution; CVD: Cardiovascular Disease; CVS: Cardiovascular System; DBP: Diastolic Blood Pressure; FMD: Flow-Mediated Dilation; GTN: Glyceryltrinitrate Dilation; HDL-C: High Density Lipoprotein Cholesterol; IDF: International Diabetic Federation; IMT: Intima-Media Thickness; LDL-C: Low Density Lipoprotein Cholesterol; MS: Metabolic Syndrome; PM2.5: Particulate Matters <2.5 Microns in Diameter; SBP: Systolic Blood Pressure; TG: Triglycerides; WHO: World Health Organization

\section{Introduction}

Cardiovascular Disease (CVD) is the leading cause of mortality and morbidity worldwide [1]. Each year over 400 million of new CVD cases are identified, accounting for 1.8 million deaths from CVD. Of the 7 million premature deaths each year linked to air pollution, 34\% are related to ischemic heart disease, $21 \%$ to respiratory disease and $20 \%$ due to stroke [2,3]. A number of traditional risk factors have been implicated, including modifiable and non-modifiable factors. In addition, there is emerging evidence showing that small particulate matters (PM2.5) air pollution and Metabolic Syndrome (MS) are important novel risk factors, for the development of atherosclerosis [4-8].

It is now possible to assess early atherogenic process more objectively and noninvasively by ultrasonography. Both flowmediated dilation (FMD) and carotid Intima-media thickness (IMT) have been shown to be reliable and reproducible atherosclerotic surrogates, significantly correlated with endothelial physiology, severity and extent of coronary artery disease, and predictive of subsequent stroke and coronary events $[9,10]$.

PM2.5 air pollution exposure has been associated with arterial endothelial dysfunction, intima-media thickening as well as computer tomography-derived coronary calcification [10-14]. MS is highly prevalent in the USA and most western countries $(22-43.3 \%)[15,16]$.
Austin J Public Health Epidemiol - Volume 8 Issue 2 - 2021 ISSN : 2381-9014 | www.austinpublishing group.com Woo et al. @ All rights are reserved
Citation: Woo KS, Timothy KCY, Chook P, Hu YJ, Yin YH, Lin CQ, et al. Independent Effects of Metabolic Syndrome and Air Pollution (PM2.5) on Atherosclerosis in Modernizing China. Austin J Public Health Epidemiol. 2021; 8(2): 1097 
The prevalence of MS in Chinese populations is comparatively lower (5.3-15\%), but has been increasing in recent years, being higher in male versus female, and in urban versus rural areas $[17,18]$. We have previously reported a higher prevalence of MS among ex-farmers (43.2\%), compared with farming residents in 3-Gorges Territories [19].

MS is associated will insulin resistance, diabetes mellitus, stroke and CVD [20]. In China, many rural Chinese are undergoing rapid economic transition and modernization, with increasing prevalence of atherosclerotic disease. We therefore proposed a study to evaluate the impact of PM2.5 air pollution and metabolic syndrome, as well as their interaction if any, on atherogenesis in modernizing China.

\section{Subjects and Methods}

In our Chinese Atherosclerotic Study in the Aged and Young (CATHAY Study), 1557 Han Chinese adults (aged 47.2 \pm 11.8 yrs, male 47\%) in Hong Kong, Macau, Pan Yu, Yu County (Shanxi coal mine area), and 3-Gorges Territories of Yangtze River (Wu Shan, Da Cheong, Fuling and Kai County) were studied. The project protocol and previous findings have been outlined and published previously [21-24]. All subjects recruited were asymptomatic and apparently healthy. They were not known to have MS or more than 2 MS components, had no known major vascular, hepatic or renal diseases, and were not taking any regular medications or vitamin supplements.

After fasting for 14 hours and providing written informed consent, their CVD profiles (smoking status, body mass index, BMI, waist circumference and waist-hip ratio WHR, systolic and diastolic pressure SBP, DBP) were evaluated. Blood was taken for lipid profiles (high-density cholesterol HDL-C, low-density cholesterol LDL-C, and triglycerides TG) and fasting glucose. Ultrasonic scan of brachial and carotid arteries were performed. Bloods were assayed in batches at the Hospital Central Conde de Januarie, Macau, the Prince of Wales Hospital, Hong Kong and the Second Hospital of Chongqing Medical University, all currently accredited by the USA laboratory centers.

Metabolic Syndrome (MS) was diagnosed during screening (Figure 1A and 1B) according to International Diabetes Federation (IDF) criteria, with lower threshold of central obesity, HDL-C, TG and SBP, compared with other criteria $[19,25,26]$.

The average long-term satellite-derived PM2.5 concentration over China was evaluated by satellite remote sensing technology, with a correlation coefficient of $>0.9$ and a mean absolute percentage error within $\pm 20 \%$ compared with ground observations [27-28]. These informations were accessible in Hong Kong, Macau and Pan Yu from 1991, but in other locations from 2001 only. Therefore, the mean yearly PM2.5 levels at the period 2001-2010 were computed in assessing the stability of PM2.5 exposure in each location.

Our institutional research ethics committee at the Chinese University of Hong Kong approved the research study and informed consent form (Reference CRE. 2000-108 \& CRE. 2018-157). This study complied with the 1995 and 2003 Declarations of Helsinki for human studies.

\section{Vascular studies}

Brachial endothelial function (flow-mediated dilation FMD) was studied by using high-resolution ultrasound, as described previously [29-31]. In brief, the diameter of brachial artery was measured on B-mode ultrasonic images, using a linear array transducer (L105) with a median frequency of $7.5 \mathrm{MHz}$, and a standard Advanced Technology Laboratories (ATL 3000 USA) or Sonosite (model Micromaxx, Bothell, USA) system. Forearm tourniquet cuff placement was adopted to induce reactive hyperemia on deflation. Scans were acquired at rest (baseline), during reactive hyperemia (to induce endothelium-dependent dilation, FMD) and after $200 \mu \mathrm{g}$ sublingual glyceryltrinitrate (GTN, an endothelium-independent dilator). Hyperemia as an indicator of the stimulus to endothelium was calculated as the \% increase in blood flow after cuff deflation compared with baseline. FMD and GTN were expressed as \% dilation from baseline vessel diameter.

Carotid Intima-media thickness (IMT) was also measured by ultrasound, using a standardized scanning protocol for both left and right carotid arteries [32-34]. Images of the far wall of the distal $10 \mathrm{~mm}$ of the common carotid artery were used. All IMT measurements were evaluated by a verified automatic edge-detecting and measurement software package, with an intra-observer variability for mean IMT of $0.03 \pm 0.01 \mathrm{~mm}$ (Coefficient of Variation $1 \%, \mathrm{R}=0.99$ ).

\section{Statistical analysis}

Data was processed to give group mean values, standard deviations, and 95\% confidence intervals (CI), when appropriate. Normal distribution was assessed by standard testing of normality of distribution. Intergroup differences were tested with independent samples Students' $t$-test and a one-way ANCOVA model. The primary study endpoints were brachial FMD and carotid IMT, while other outcome variables were compared after Bonferroni adjustment for multiple comparisons. On the assumption of mean brachial FMD being $7.3 \%$ and mean carotid IMT being $0.63 \pm 0.14 \mathrm{~mm}$ in the cohort, we estimated that identification of 310 subjects with MS and 1200 subjects without MS would result in adequate power (85\%) to detect a $10 \%$ difference in brachial FMD, and a power of $85 \%$ to detect a $10 \%$ difference in carotid IMT between the group with MS and group without MS at the $\mathrm{p}<0.05$ (2-sided) difference level [35]. Multivariate regression analysis was performed to assess the annuitants of MS development, including age, gender smoking status, PM2.5, BMI, LDL-C and location areas. Linear multivariate regression analyses were then carried out to assess the major determinants of FMD or IMT of the entire cohort, including age, smoking status, gender, PM2.5 exposure, metabolic syndrome, LDL-C, and the 3 location areas. Similar multivariate regression was performed separately to assess the determinants of FMD and IMT, in the MS cohort and the cohort without MS. The variables with significant standardized beta coefficients (beta value with $\mathrm{p}<0.05$ ) in the regression model were identified, and insignificant variables ( $p$ value $>0.05$ ) were subsequently removed. The interaction effect was examined by including the interaction term (product of MS and PM2.5) into the model. Group differences with an error probability of less than 5\% $(2 p<0.05)$ were considered statistically significant. Statistical analyses were performed with SPSS version 22.

\section{Results}

\section{Cardiometabolic health parameters}

The mean yearly PM2.5 air pollution was tabulated, ranging 

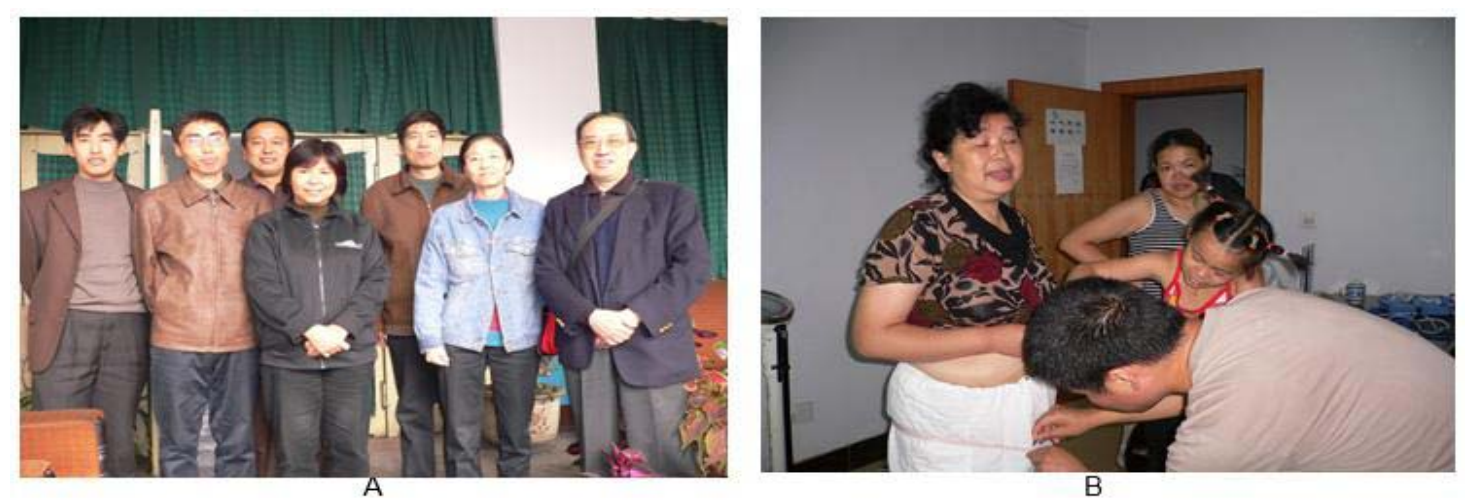

Figure 1A and 1B: Cohort without metabolic syndrome in Hong Kong and Yu County (Figure $1 \mathrm{~A})$ and subjects with metabolic syndrome in Wu Shan (Figure 1B).

Table 1: Yearly Air Pollution (PM2.5) exposure in 1557 Subjects.

\begin{tabular}{|c|c|c|c|c|}
\hline \multirow{2}{*}{ Location } & \multirow{2}{*}{$\begin{array}{c}\text { Mean PM2.5 }\left(\mu \mathrm{g} / \mathrm{m}^{3}\right) \\
(2001-2010)\end{array}$} & \multicolumn{3}{|c|}{ PM2.5 Exposure } \\
\hline & & Year of Study & Number of Subjects & PM2.5 $\left(\mu \mathrm{g} / \mathrm{m}^{3}\right)$ \\
\hline \multicolumn{5}{|l|}{ Location 1} \\
\hline Hong Kong & 37 & 1991-2002 & 147 & $34.0-36.2$ \\
\hline Macau & 41.3 & 1998-2001 & 201 & $40.4-44.8$ \\
\hline \multicolumn{5}{|l|}{ Location 2} \\
\hline Pan Yu & 59.2 & 1996-1997 & 161 & $52.1-55.1$ \\
\hline Yu County & 68.7 & $2000-2003$ & 344 & $70.3-73.0$ \\
\hline \multicolumn{5}{|l|}{ Location 3} \\
\hline \multicolumn{5}{|l|}{3 Gorges } \\
\hline Wu Shan & 74.1 & $2005-2007$ & 114 & $72.2-86.9$ \\
\hline Da Cheong & 77.8 & 2006 & 245 & 93.8 \\
\hline Kai County & 52.5 & 2007 & 191 & 47.9 \\
\hline
\end{tabular}

PM2.5: Particulate matters $<2.5$ microns in diameter.

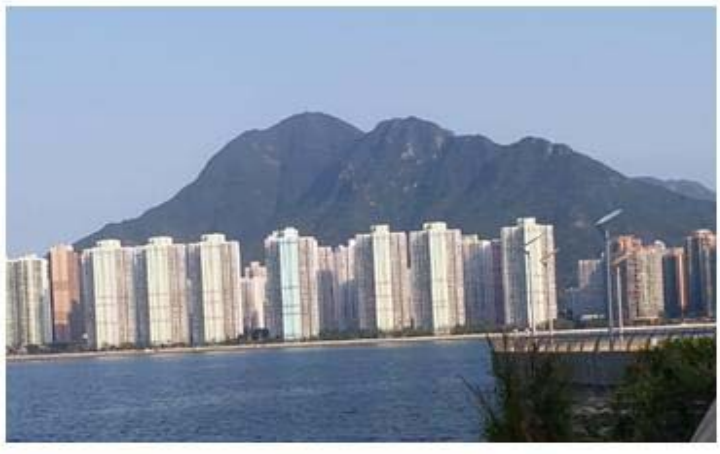

A

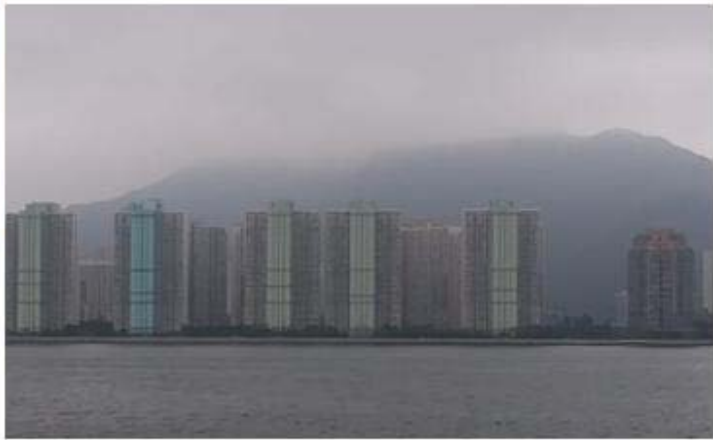

B

Figure 2A and 2B: View of Shatin along the Shing Moon River, Hong Kong on clear day (Figure $2 \mathrm{~A}$ ) with PM2.5 level of $14 \mu \mathrm{g} / \mathrm{m}^{3}$ and on polluted day with PM2.5 level of $45 \mu \mathrm{g} / \mathrm{m}^{3}$ (Figure 2B) (Courtesy of Prof KS Woo).

from 34.0-44.8 $\mu \mathrm{g} / \mathrm{m}^{3}$ in Hong Kong and Macau to $93.8 \mu \mathrm{g} / \mathrm{m}^{3}$ in Da Cheong (Table 1 and Figure $2 \mathrm{~A}$ and $2 \mathrm{~B}$ ). These differed from the mean PM2.5 in 2001-2010 by $<17.0 \%$. Metabolic syndrome was diagnosed in 340 subjects $(21.8 \%)$. Their smoking status, gender, PM2.5, and LDL-cholesterol were similar to the cohort without MS ( $n=1217)$, but age $(\mathrm{p}=0.041)$, SBP $(\mathrm{p}<0.001)$, DBP $(\mathrm{p}<0.001)$, waist circumference $(\mathrm{p}=0.03)$, TG $(\mathrm{p}<0.001)$, and blood glucose $(\mathrm{p}<0.001)$ were higher, and HDL-C was lower $(\mathrm{p}<0.001)$ in the MS group (Table 2).

\section{Vascular measures}

Brachial FMD was significantly lower $(7.3 \pm 2 \%, 95 \%$ CI $6.8-7.6 \%)$ in the MS cohort as compared with those without MS, $(8.1 \pm 2.6 \%$, 
Table 2: Cardiovascular Risk Factors in Cohort with or Without Metabolic Syndrome.

\begin{tabular}{|c|c|c|c|}
\hline & MS Cohort & MS negative Cohort & P-Values* \\
\hline & $(\mathrm{N}=340) 21.8 \%$ & $(\mathrm{~N}=1217)$ & (Bonferroni adjustment) \\
\hline PM2.5 $\left(\mu \mathrm{g} / \mathrm{m}^{3}\right)$ & $65.6 \pm 17.2$ & $61.5 \pm 18.9$ & 0.95 \\
\hline Age (yrs) & $51.0 \pm 9.7$ & $46.1 \pm 12.9$ & 0.04 \\
\hline Male (\%) & 46.2 & 48.1 & 0.9 \\
\hline Smoking (\%) & 26.7 & 26.4 & 0.99 \\
\hline $\mathrm{SBP}(\mathrm{mmHg})$ & $134.6 \pm 17.1$ & $118.8 \pm 15.8$ & $<0.001$ \\
\hline $\mathrm{DBP}(\mathrm{mmHg})$ & $86.1 \pm 9.7$ & $76.4 \pm 10.0$ & $<0.001$ \\
\hline Waist circumference $(\mathrm{cm})$ & $87.1 \pm 8.6$ & $76.1 \pm 8.4$ & 0.03 \\
\hline LDL-C (mmol/l) & $2.9 \pm 1.0$ & $2.8 \pm 1.0$ & 0.062 \\
\hline $\mathrm{TG}(\mathrm{mmol} / \mathrm{l})$ & $2.1 \pm 1.6$ & $1.1 \pm 0.8$ & $<0.001$ \\
\hline HDL-C (mmol/l) & $1.01 \pm 0.21$ & $1.27 \pm 0.35$ & $<0.001$ \\
\hline Glucose (mmol/l) & $6.0 \pm 1.3$ & $5.3 \pm 0.9$ & $<0.001$ \\
\hline
\end{tabular}

*Comparing MS cohort vs. No MS Cohort.

DBP: Diastolic Blood Pressure; HDL-C: High Density Lipoprotein Cholesterol; LDL-C: Low Density Lipoprotein Cholesterol; MS: Metabolic Syndrome; SBP: Systolic Blood Pressure; TG: Triglycerides.

Table 3: Vascular Parameters in Cohort with and Cohort without Metabolic Syndrome.

\begin{tabular}{|c|c|c|c|c|}
\hline & Overall & MS Cohort & No MS Cohort & P-value* $^{*}$ \\
\hline Brachial FMD (\%) & $7.92 \pm 2.52$ & $7.26 \pm 2.03$ & $8.10 \pm 2.60$ & $<0.0001$ \\
\hline$(95 \% \mathrm{Cl})$ & $(7.73-8.10)$ & $(6.82-7.60)$ & $(7.88-8.32)$ & \\
\hline GTN (\%) & $18.2 \pm 4.2$ & $17.3 \pm 3.3$ & $18.5 \pm 4.4$ & 0.68 \\
\hline$(95 \% \mathrm{Cl})$ & $(17.9-18.5)$ & $(16.8-17.9)$ & $(18.1-18.9)$ & \\
\hline Hyperemia & $674.9 \pm 261.7$ & $640.6 \pm 243.1$ & $693.3 \pm 260.6$ & 0.48 \\
\hline$(95 \% \mathrm{Cl})$ & $(655.7-694.0)$ & $(598.9-882.3)$ & $(671.1-715.4)$ & \\
\hline Carotid IMT (mm) & $0.65 \pm 0.14$ & $0.70 \pm 0.13$ & $0.63 \pm 0.14$ & $<0.0001$ \\
\hline$(95 \% \mathrm{Cl})$ & $(0.64-0.65)$ & $(0.66-0.71)$ & $(0.62-0.64)$ & \\
\hline
\end{tabular}

${ }^{*}$ Comparing MS Cohort vs. No MS Cohort.

FMD: Flow-Mediated Dilation; GTN: Glyceryltrinitrate Dilation; IMT: Intima-Media Thickness; MS: Metabolic Syndrome.

95\% CI 7.9-8.3\% $\mathrm{p}<0.0001)$. Carotid IMT was greater in those with versus without $\mathrm{MS}(0.7 \pm 0.13 \mathrm{~mm}, 95 \%$ CI $0.68-0.71 \mathrm{~mm}$ versus $0.63 \pm 0.14 \mathrm{~mm} 95 \%$ CI $0.62-0.64 \mathrm{~mm}, \mathrm{p}<0.0001)$. The hyperemia and GTN responses were similar in the 2 cohorts (Table 3 ).

\section{Multivariate regression analyses}

PM2.5 level was similar in cohort with or without MS ( $\mathrm{p}=0.95)$ (Table 2). Multivariate regression did not reveal any significant role of AP on development of MS (Table 4).

On multivariate regression of the entire cohort ( $\mathrm{n}=1557)$, PM2.5 was significantly related to carotid IMT (beta $=0.422, \mathrm{p}<0.0001$ ), independent of MS (beta $=0.103, p<0.0001)$, male gender (beta $=0.105$, $\mathrm{p}<0.0001)$, age (beta $=0.475, \mathrm{p}<0.0001)$, BMI (beta $=0.066, \mathrm{p}=0.013)$, LDL-C (beta $=0.102, \mathrm{p}<0.0001)$ and location (beta $=-0.151, \mathrm{p}=0.002)$, but not smoking status (model $\mathrm{R}^{2}=0.443, \mathrm{~F}$-value $=98.9$, $\mathrm{p}$-value $<0.0001$ ) (Table 5). However, only male gender (beta $=-0.169$, $\mathrm{p}=0.0001)$, age (beta $=-0.143, \mathrm{p}=0.001)$ and location $(\mathrm{beta}=-0.210$, $\mathrm{p}=0.03)$ were related to FMD, but not PM2.5 nor other risk factors (model $\mathrm{R}^{2}=0.081, \mathrm{~F}$-value $=7.03$, $\mathrm{p}$-value $<0.0001$ ).

In the MS cohort $(\mathrm{n}=340)$, PM2.5 (beta $=0.245, \mathrm{p}<0.0001$ ), was related to carotid IMT, independent of age (beta $=0.255, \mathrm{p}=0.001$ ),
Table 4: Determinants of Metabolic Syndrome Development in Whole Cohort.

\begin{tabular}{|c|c|c|}
\hline Risk Factors & Beta-Value & P-value \\
\hline PM2.5 & -0.029 & 0.609 \\
\hline Male gender & -0.065 & 0.045 \\
\hline Age & -0.186 & $<0.0001$ \\
\hline Smoking Status & -0.031 & 0.338 \\
\hline BMI & -0.419 & $<0.0001$ \\
\hline LDL-C & -0.018 & 0.338 \\
\hline Location 1_2_3 & 0.011 & 0.85 \\
\hline
\end{tabular}

${ }^{*}$ Model $\mathrm{R}^{2}=0.218, \mathrm{~F}$-value $=40.87, \mathrm{p}<0.0001$.

BMI: Body Mass Index; LDL-C: Low Density Lipoprotein Cholesterol; PM2.5: Particulate Matters $<2.5$ microns in diameter.

Table 5: Determinants of Risk Factors for Vascular Parameters in Whole Cohort.

\begin{tabular}{|c|c|c|c|c|}
\hline \multirow{2}{*}{ Risk Factors } & \multicolumn{2}{|c|}{ Brachial FMD* } & \multicolumn{2}{c|}{ Carotid IMT** } \\
\cline { 2 - 5 } & Beta-Value & P-value & Beta-Value & P-value \\
\hline PM2.5 & 0.109 & 0.274 & 0.422 & $<0.001$ \\
\hline Metabolic Syndrome & -0.001 & 0.983 & 0.103 & $<0.0001$ \\
\hline Male gender & -0.169 & $<0.0001$ & 0.105 & $<0.0001$ \\
\hline Age & -0.143 & $<0.0001$ & 0.478 & $<0.0001$ \\
\hline BMI & -0.073 & 0.117 & 0.066 & 0.018 \\
\hline LDL-C & -0.012 & 0.809 & 0.102 & $<0.0001$ \\
\hline Smoking Status & -0.066 & 0.151 & 0.052 & 0.058 \\
\hline Location 1_2_3 & -0.21 & 0.03 & -0.151 & 0.002 \\
\hline
\end{tabular}

${ }^{*}$ Model $R^{2}=0.081, F$-value $=7.03, p<0.0001$

${ }^{* *}$ Model $R^{2}=0.443, F$-value=98.9, $p<0.0001$.

BMI: Body Mass Index; LDL-C: Low Density Lipoprotein Cholesterol; PM2.5 Particulate Matters $<2.5$ microns in diameter.

SBP (beta $=0.350, p=0.002$ ), and waist circumference (beta $=0.187$, $\mathrm{p}=0.006$ ), (model $\mathrm{R}^{2}=0.30, \mathrm{~F}$-value $=7.87$, $\mathrm{p}$-value $<0.0001$ ). In the cohort without MS ( $\mathrm{n}=1217)$, PM2.5 was related to carotid IMT (beta $=0.234, \mathrm{p}<0.0001)$, independent of age (beta $=0.455, \mathrm{p}<0.0001)$, SBP (beta $=0.279, \mathrm{p}<0.0001$ ), waist (beta $=0.0969, \mathrm{p}=0.009$ ), and DBP (beta $=-0.138, \mathrm{p}=0.015), \quad\left(\right.$ model $\mathrm{R}^{2}=0.452, \mathrm{~F}$-value $=36.4, \mathrm{p}$-value $<0.0001$ ) (Table 6). Brachial FMD was related to male gender and 
Table 6: Determinants of Risk Factors for Carotid IMT in Cohort with and Without Metabolic Syndrome.

\begin{tabular}{|c|c|c|c|c|}
\hline \multirow{2}{*}{ Risk Factors } & \multicolumn{2}{|c|}{ MS Cohort* } & \multicolumn{2}{c|}{ MS negative Cohort ${ }^{\star *}$} \\
\cline { 2 - 5 } & Beta-Value & P-value & Beta-Value & P-value \\
\hline Male gender & 0.145 & 0.93 & 0.076 & 0.204 \\
\hline Age & 0.255 & 0.001 & 0.455 & $<0.0001$ \\
\hline SBP & 0.35 & 0.002 & 0.279 & $<0.0001$ \\
\hline DBP & -0.169 & 0.12 & -0.138 & 0.015 \\
\hline Smoking & 0.095 & 0.211 & 0.057 & 0.163 \\
\hline HDL-C & 0.006 & 0.933 & 0.039 & 0.293 \\
\hline Waist & 0.187 & 0.006 & 0.0969 & 0.009 \\
\hline Blood Glucose & 0.028 & 0.668 & 0.045 & 0.194 \\
\hline LDL-C & 0.067 & 0.32 & 0.052 & 0.132 \\
\hline Triglycerides & 0.08 & 0.206 & 0.017 & 0.647 \\
\hline PM2.5 & 0.245 & $<0.001$ & 0.234 & $<0.0001$ \\
\hline Locations 1_2_3 & -0.089 & 0.233 & 0.005 & 0.918 \\
\hline
\end{tabular}

${ }^{*} R^{2}=0.30, F$ value $=7.87, p<0.0001$.

${ }^{* *} R^{2}=0.452, F$ value $36.4, p<0.0001$

DBP: Diastolic Blood Pressure; HDL-C: High Density Lipoprotein Cholesterol; LDL-C: Low Density Lipoprotein Cholesterol; MS: Metabolic Syndrome; PM2.5: Particulate Matters <2.5 Microns in Diameter; SBP: Systolic Blood Pressure.

Table 7: Determinant of Brachial FMD in Cohort with and Without Metabolic Syndrome.

\begin{tabular}{|c|c|c|c|c|}
\hline \multirow{2}{*}{ Risk Factors } & \multicolumn{2}{|c|}{ MS Cohort* } & \multicolumn{2}{c|}{ MS negative Cohort ${ }^{\star *}$} \\
\cline { 2 - 5 } & Beta-Value & P-value & Beta-Value & P-value \\
\hline Male gender & -0.298 & 0.029 & -0.248 & 0.005 \\
\hline Age & -0.456 & 0.003 & -0.174 & 0.024 \\
\hline SBP & 0.204 & 0.33 & -0.008 & 0.939 \\
\hline DBP & -0.338 & 0.096 & -0.122 & 0.251 \\
\hline Smoking & -0.007 & 0.954 & -0.0547 & 0.569 \\
\hline Waist & -0.02 & 0.87 & -0.19 & 0.016 \\
\hline HDL-C & 0.157 & 0.222 & 0.048 & 0.514 \\
\hline LDL-C & 0.073 & 0.548 & -0.047 & 0.527 \\
\hline Triglycerides & 0.047 & 0.681 & -0.137 & 0.052 \\
\hline Glucose & -0.264 & 0.094 & -0.033 & 0.635 \\
\hline PM2.5 & 0.049 & 0.7 & -0.032 & 0.688 \\
\hline Locations 1_2_3 & 0.206 & 0.126 & 0.091 & 0.253 \\
\hline
\end{tabular}

*Model $\mathrm{R}^{2}=0.197, \mathrm{~F}$-value $=2.51, \mathrm{p}=0.009$.

${ }^{*}$ Model $R^{2}=0.134$, F-value $=3.69, p<0.0001$.

DBP: Diastolic Blood Pressure; HDL-C: High Density Lipoprotein Cholesterol

LDL-C: Low Density Lipoprotein Cholesterol; PM2.5: Particulate Matters <2.5 Microns in Diameter.

age (in both cohorts) and additionally waist circumference (in MS negative cohort), but not to PM2.5 nor locations (Table 7). The direct interaction effect of MS and PM2.5 on carotid IMT was not significant (beta $=0.089, \mathrm{p}=0.895$ ).

\section{Discussion}

PM2.5 air pollution has been related to CVD and mortality. In our study, both PM2.5 and MS were associated with these early atherogenic processes. The MS prevalence $(21.6 \%)$ observed in the current study is comparable to those in most western countries $[15,16]$.
We have previously reported lifestyle and dietary changes during modernization in China are associated with a 3-fold increase in the prevalence of MS, with implications for atherosclerosis prevention [36]. Our present study confirmed both PM2.5 air pollution and metabolic syndrome have significant and independent impacts on athergenesis in modernizing China, independent of traditional atherosclerotic risk factors. Although no direct interaction effect of MS and PM2.5 could be demonstrated, there was different impact of PM2.5 concentration and metabolic syndrome on atherogenic process. While PM2.5 have similar impact on carotid IMT (beta values $0.234-0.245$ ) in those with MS versus those without MS, the regression model in $\mathrm{MS}$ cohort $\left(\mathrm{R}^{2}=0.30, \mathrm{~F}\right.$-value $\left.=7.87, \mathrm{p}<0.0001\right)$ suggested a less contribution of PM2.5 and other atherosclerotic risk factors to carotid IMT than in the cohort without MS $\left(\mathrm{R}^{2}=0.452\right.$, $\mathrm{F}$-value $=36.4, \mathrm{p}<0.0001)$. These novel findings will support the need to tackle both the PM2.5 problem and other atherosclerosis risk factors (SBP, DBP and waist) for the prevention of atherosclerosis in subjects not yet developing MS. Putting in pertinent clinical context, PM2.5 together with other traditional risk factors would account for $30 \%$ of variation in carotid IMT in MS cohort, compared with $45 \%$ in cohort without MS.

Brachial FMD, another predictive atherosclerotic surrogate marker, was worse $(7.3 \pm 2.0,95 \%$ CI 6.8-7.6\%) in MS adults compared to those without MS (8.1 $\pm 2.6,95 \%$ CI 7.9-8.3\%), but our multivariate regression model did not confirm any significant impact of MS, independent of traditional risk factors. While carotid IMT would reflect the long-term impact on atherogenic process, FMD is likely more dynamic and vulnerable to changes in more labile risk factors, including blood pressure, lipid profiles and blood glucose. Similarly, different locations could be confounding factor regarding possible novel risk factors for FMD and IMT, such as lifestyle, socioeconomic and dietary habits in the different locations studied [36-39]. In our regression models in the 2 cohorts with or without MS, however, there was no significant impact of PM2.5 on the FMD surrogate marker. Our findings reierate previous report documenting MS is related to vascular structural alteration but not to functional ones [40].

To contextualize the magnitude of IMT difference observed in the current study, where we found a mean difference of $0.07 \mathrm{~mm}(11.1 \%)$ between the cohort with and cohort without MS, a $0.16 \mathrm{~mm}$ increase in carotid IMT has been associated with a $41 \%$ increase in stroke and $43 \%$ increase in acute myocardial infarction over a period of 2.7 years [33]. The $11 \%$ difference in carotid IMT was approximately similar to the kind of difference found between diabetic and non-diabetic Chinese adults [24]. Measurement of carotid IMT can be easily accessible at a relatively low cost. While other more sophisticated cardiac parameters, such as cardiac magnetic resonance scan or CT-derived coronary calcification, may be more predictive of cardiovascular events, a recent meta-analysis of 119 clinical trials on carotid IMT progression has documented the predictive value of IMT reduction on CVD events [41]

The central government in China, like many other developing countries, has adopted a green environment-friendly policy to help sustaining economic transition and modernization [42]. However, in the coming 1-2 decades, PM2.5 air pollution could still exceed the safe level of $<20 \mu \mathrm{g} / \mathrm{m}^{3}$ advocated by WHO, and accordingly would pose an important environmental problem compared with many countries 
in the western world [43]. While traditional risk factors should be dealt with and optimally addressed, our present study proposes, in addition, emphasis on both air pollution and metabolic syndrome. Arterial intima-media thickening is an upstream precursor of plaque formation and CVS events [41,44]. To prevent such atherogenic processes, practical strategies to reduce both PM2.5 air pollution and metabolic syndrome should be considered. Physical activity promotion to avoid MS development [36-39,45], adoption of global and country-wide policies on air pollution, $[42,46]$ and personalized strategies of wearing facial mask, [47] usage of air filtering or other purifying devices at home [48-51] are potential options, in this regard.

\section{Study Limitations}

Our study did not address exposure to indoor PM2.5 air pollution, which may be different from outdoor PM2.5 concentrations, in different locations [52-54]. Real-time measurement by portable devices can provide more accurate PM2.5 level, but the short measurement duration limits the ability to evaluate long-term average levels. One potential limitation of the present project is studying different locality in China in different period from 1991 to 2007. Over this period, the PM2.5 exposure appeared to be quite stable (within 17\%) in these Chinese locations, hence justifying the meaningful comparison in the present study. Moreover, other biological parameters to assess PM2.5-induced inflammation, such as high sensitivity $\mathrm{C}$ reactive protein, fibrinogen and cytokines were not assessed, which may be more relevant to metabolic syndromerelated atherogenesis. No detrimental effects of smoking on vascular parameters was demonstrated, possibly related to less impact on carotid IMT or brachial FMD in rural Chinese, compared with urbanized Chinese, as reported previously [21]. Lastly different lifestyle, dietary habits, socioeconomic profiles and psychological stressors were not evaluated, in our study. However we have previously documented a detrimental impact of lifestyle changes on cardiometabolic health in modernizing China [36].

\section{Conclusions}

Both PM2.5 air pollution and MS have independent impacts on atherosclerotic process in modernizing China, with potential implications for atherosclerosis prevention.

\section{Data Availability}

The research data will be available from the corresponding author to the editor and readers on reasonable request.

\section{Funding}

This work was supported by The Chinese Atherosclerosis Trust, Madam Leung Kit Wah Project Fund, Dr. Stanley Ho Medical Development Foundation (grant \& donation), Star Industrial Company and Dr. Thomas HC Cheung Trust: They provided unrestricted sponsorship for the present study, without any involvement in study design, data collection, analysis or interpretation, nor in the writing of this report or the decision to submit the paper for publication.

\section{Acknowledgements}

We wish to acknowledge the valuable support of the Chinese Atherosclerosis Trust, Leung Kit Wah Project Fund, Dr. Stanley
Ho Medical Development Foundation Trust, the Star Industrial Company Fund of The Chinese University of Hong Kong and Dr. Thomas HC Cheung Trust in sponsoring the study. We also acknowledge Mr. Jimmy Zhu of the Macau Heart Foundation, for helping recruitment of subjects, and the Pathology Department of Centro Hospitalar Conde de Sao Januario in Macau for the blood assays. We acknowledge the superb statistical analyses and clerical work of Mr. Jason Leung, Miss Mikki Wong, and Ms. Daphne Chu, of The Chinese University of Hong Kong.

\section{Conflict of Interest}

We declare no financial interests or connections, direct or indirect, or other situations that might raise the question of bias in the work reported or the conclusions, implications or opinions stated - including pertinent commercial or other sources of funding for the individual author(s) or for the associated department(s) or organization(s), personal relationships, or direct academic competition.

\section{Author Contribution}

WOO KS: Project conception and design, research administration, statistical analysis and interpretation of data, drafting and revision of the article and final approval of the version to be published.

Kwok CY, Timothy: Design of project, interpretation of data, revision of the article and final approval of the version to be published.

Chook Ping: Project conception and design, performance of ultrasonography analysis and interpretation of data, drafting, revision of the article and final approval of the version to be published.

Hu YJ: Research data collection, performance of ultrasonography analysis and interpretation of data, revision of the article and final approval of the version to be published.

Yin YH: Project conception, interpretation of data, revision of the article and final approval of the version to be published.

Lin CQ: Provision and interpretation of PM2.5 data in China.

Lau KHA: Provision of PM2.5 data, interpretation of data, revision of the article and final approval of the version to be published.

Lee PWA: Analysis and interpretation of data, revision of the article and final approval of the version to be published.

Celemajer DS: Project conception and design, interpretation of data, drafting and revision of the article, and final approval of the version to be published. All authors agree to be accountable for all aspects of the works.

All authors agree to be accountable for all aspects of the works.

\section{Highlights}

In our cross-sectional study in 9 locations in China, we confirmed PM2.5 air pollution and metabolic syndrome have independent impacts on atherogenic process, with implication for atherosclerosis prevention.

\section{References}

1. Lloyd-Jones D, Adams R, Carnethon M, et al. American Heart Association Statistics Committee and Stroke Statistics Subcommittee. Heart disease and 
stroke statistics-2009 update: A report from the American Heart Association Statistics Committee and Stroke Statistics Subcommittee. Circulation. 2009; 119: $480-486$.

2. Roth GA, Johnson C, Abajobir, et al. Global regional and national burden of cardiovascular diseases for 10 causes, 1990-2015. J Am Coll Cardiol. 2017 70: $1-25$

3. Jasarevic T, Thomas G, Osseiran N. 7 million premature deaths annually lined to air pollution. WHO Media Centre. 2014

4. Rajagopalan S, Al-Kini SG, Brook RD. Air pollution and cardiovascular disease. J AM Coll Cardiol. 2018; 72: 2054-2070.

5. Pope III CA, Burnett RT, Thurston GD, et al. Cardiovascular mortality and long-term exposure to particular air pollution - Epidemiological evidence of general pathophysiological pathways of disease. Circulation. 2004; 109: 71 77.

6. Cameron AJ, Shaw JE, Zimmet PZ. The metabolic syndrome: Prevalence in worldwide populations. Endocrinal Metab Clin North Am. 2004; 33: 351-375.

7. Danaei G, Ding EL, Mozaffarian D, et al. The preventable causes of death in the United States: Comparative risk assessment of dietary, lifestyle, and metabolic risk factors. PLoS Med. 2009; 6: 1-23.

8. Künzli N, Jerrett M, Mack WJ, Beckerman B, LaBree L, Gilliland F, et al Ambient air pollution and atherosclerosis in Los Angeles. Environ Health Perspect. 2005; 113: 201-206.

9. Anderson TJ, Uehata A, Gerhard MD, et al Close relation of endothelia function in the human coronary and peripheral circulations. J Am Coll Cardiol. 1995; 26: 1235-1241.

10. O'Leary DH, Polak JF, Kronmal RA, Manolio TA, Burke GL, Wolfson Jr SK. Carotid-artery intima and media thickness as a risk factor for myocardia infarction and stroke in older adults. N Engl J Med. 1999; 340: 14-22.

11. Diez Roux AV, Auchincloss AH, Franklin TG, et al. Long-term exposure to ambient particulate matter and prevalence of subclinical atherosclerosis in the Multi-Ethnic Study of Atherosclerosis. Am J Epidemiol. 2008; 167: 667675

12. Bauer M, Moebus S, Möhlenkamp S, et al. HNR Study Investigative Group. Urban particulate matter air pollution is associated with subclinical atherosclerosis: results from the HNR (Heinz Nixdorf Recall) study. J Am Coll Cardiol. 2010; 56: 1803-1808.

13. Huynh Q, Marwick TH, Venkataraman P, Knibbs LD, Johnston FH, and Negishi K. Long-term exposure to ambient air pollution is associated with coronary artery calcification among asymptomatic adults. European Heart $\mathrm{J}$ Cardiovascular Imaging. 2020: 1-8.

14. Woo KS, Chook P, Hu YJ, et al. The Impact of Particulate Matter Air Pollution (PM2.5) on Atherosclerosis in Modernizing China: the report from CATHAY Study. Inte J Epid. 2020: 1-11.

15. Mozumdar A, Liguori G. Persistent increase of prevalence of metabolic syndrome among U.S. adults: NHANES III to NHANES 1999-2006. Diabetes Care. 2011; 34: 216-219

16. Cameron AJ, Shaw JE, Zimmet PZ. The metabolic syndrome: prevalence in worldwide populations. Endocrinal Metab Clin North Am. 2004; 33: 351-375.

17. Gu DF, Reynolds K, Wu X, et al. Prevalence of the metabolic syndrome and overweight among adults in China. Lancet. 2005; 365: 1398-1405.

18. Zhan YQ, Yu JM, Chen RQ, et al. Socioeconomic status and metabolic syndrome in the general population of China: A cross-sectional study. BMC Public Health. 2012; 12: 921-927.

19. Woo KS, Hu YJ, Chook P, et al. A Tale of Three Gorges in the Yangtze River: Comparing the Prevalence of Metabolic Syndrome According to ATP III, WHO, and IDF Criteria and the Association with Vascular Health in Modernizing China. Meta Syndr Relat Disord. 2019; 17: 137-142.

20. Wilson WF, D'Agostino RB, Arise $\mathrm{H}$, et al. Metabolic syndrome as precursor of cardiovascular disease and type 2 diabetes mellitus. Circulation. 2005; 112: 3066-3072.
21. Woo KS, Robinson JT, Chook P, et al. Differences in the effect of cigarette smoking on endothelial function in Chinese and white adults. Ann Intern Med. 1997; 127: 372-375.

22. Woo KS, Chook P, Raitakari OT, McQuillan B, Feng JZ, Celermajer DS Westernization of Chinese adults and increased subclinical atherosclerosis. Arterioscler Thromb Vasc Biol. 1999; 19: 2487-2493.

23. Woo KS, McCrohon JA, Chook P, et al. Chinese Adults Are Less Susceptible Than Whites to Age-Related Endothelial Dysfunction. J Am Coll Cardiol. 1997; 30: 113-118

24. Thomas GN, Chook $\mathrm{P}$, Qiao $\mathrm{M}$, et al. Deleterious impact of "high normal" glucose levels and other metabolic syndrome components on arterial endothelial function and intima-media thickness in apparently healthy Chinese subject: The CATHAY study. Arterioscler Thromb Vasc Biol. 2004; 24: $739-743$

25. Balkau B, Charles MA. Comment on the provisional report from the WHO consultation. Diabet Med. 1999; 16: 442-443.

26. Zimmet P, Alberti K, George MM and Rios MS. A new International Diabetes Federation (IDF) worldwide definition of the metabolic syndrome: The rationale and the results. Rev Esp Cardiol. 2005; 58: 1371-1376.

27. Lin $\mathrm{CQ}$, Li Y, Yuan ZB, Lau AKH, Li, CC and Fung JCH. Using satellite remote sensing data to estimate the high-resolution distribution of ground level PM2.5. Remote Sens. Environ. 2015; 156: 117-128.

28. Lin CQ, Liu G, Lau AKH, Li Y, Li CC, Fung JCH, et al. High-resolution satellite remote sensing of provincial PM2.5 trends in China from 2001 to 2015 Atmos. Environ. 2018; 180: 110-116.

29. Celermajer DS, Sorensen K, Gooch V, Spiegelhalter DJ, Miller OI, Sullivan ID, et al. Non-invasive detection of endothelial dysfunction in children and adults at risk of atherosclerosis. The Lancet 1992; 340: 1111-1115.

30. Woo KS, Chook P, Yu CW, Sung RY, Qiao M, Leung SS, et al. Overweight in children is associated with arterial endothelial dysfunction and intima-media thickening. Int J Obes. 2004; 28: 852-857.

31. Woo KS, Chook P, Yu CW, et al. Effects of diet and exercise on obesityrelated vascular dysfunction in children. Circulation 2004; 109: 1981-1986.

32. Salonen JT, Salonen R. Ultrasonographically assessed carotid morphology and the risk of coronary heart disease. Arterioscler Thromb Vasc Biol. 1991 11: $1245-1249$

33. Bots ML, Hoes AW, Koudstaal PJ, Hofman A, Grobbee DE. Common carotid intima-media thickness and risk of stroke and myocardial infarction: The Rotterdam Study. Circulation. 1997; 96: 1432-1437.

34. Touboul PJ, Hennerici MG, Meairs S, et al. Advisory Board of the 3rd Watching the Risk Symposium 2004, 13th European Stroke Conference. Mannheim intima-media thickness consensus. Cerebrovasc Dis. 2004; 18 : 346-349.

35. Schulz Kenneth F, David A Grimes. Sample size calculations in randomised trials: mandatory and mystical. Lancet. 2005; 365: 1348-1353.

36. Woo KS, Hu YJ, Chook P, et al. The Impact of Lifestyle Changes on Cardiometabolic Health in Modernizing China: A Tale of Three Gorges in the Yangtze River. Metab Syndr Relat Disord. 2020; 18: 65-71.

37. Grundy SM, Cleeman JI, Daniel SR, et al. Diagnosis and management of the metabolic syndrome an American heart association/national heart, lung, and blood institute scientific statement. Circulation. 2005; 112: 2735-2752.

38. Wijnadele K, Duvigneaud N, Matton L, et al. Sedentary behavior, physica activity and a continuous metabolic syndrome risk score in adults. Euro J Clin Nutri. 2009; 63: 421-429.

39. Edwardson CL, Gorely T, Davies MJ, et al. Association of sedentary behavior with metabolic syndrome: a meta-analysis. PLoS One. 2012; 7: e34916.

40. A Maloberti, M Bombelli, P Vallerio, M Milani, I Cartella, G Tavecchia, et al Metabolic syndrome is related to vascular structural alterations but not to functional ones both in hypertensives and healthy subjects. Nutr, Metab \& Cardiovas Dis. 2021; 31: 1044-1052. 
41. Willeit $\mathrm{P}$, Tschiderer L, Allara Elias, Reuber $\mathrm{K}$, et al. Carotid intima-media thickness progression as surrogate marker for cardiovascular risk. (Metaanalysis of 119 clinical trials involving 100667 patients). Circulation. 2020 142: 621-642.

42. Yang J, Sin JG, Remais JV, et al. The Tsinghua-lancet commission on healthy cities in China: unlocking the power of cities for a healthy China. Lancet. 2018; 391: 2140-2184.

43. Münzel T, Miller MR, Sørensen M, Lelieveld J, Daiber A, Rajagopalan S Reduction of environmental pollutants for prevention of cardiovascula disease: it's time to act. Eur Heart J. 2020; 41: 3989-3997.

44. Pepine CJ. The effects of angiotensin-converting enzyme inhibition on endothelial dysfunction: potential role in myocardial ischemia. Am J Cardiol. 1998; 82: 23S-27S.

45. Romieu I, Castro-Giner F, Dunzli N and Sunyer J. Air pollution, oxidative stress and dietary supplementation: a review. Eur Respir J. 2008; 31: 179 196.

46. Baumgartner J, Smith KR, Chockalingam A. Reducing CVD through improvements in household energy - Implications for policy-relevant research. Global Heart. 2012; 7: 243-247.

47. Langrish JP, Mils NL, Chan JKK, et al. Beneficial cardiovascular effects of reducing exposure to particulate air pollution with a simple facemask. Particle and Fibre Toxicology. 2009; 6: 8.

48. Vieira JL, Guimaraes GV, Andre PA, Cruz FD, Saldiva PHN, Bocchi EA Respiratory filter reduces the cardiovascular effects associated with diesel exhaust exposure. J Am Coll Cardiol HF. 2016; 4: 55-64.
49. Allen RW, Carlsten C, Karlen B, Leckie S, Eeden SV, Vedal S, et al. An air filter intervention study of endothelial function among healthy adults in a woodsmoke-impacted community. Am J Respir Crit Care Med. 2011; 183: 1222-1230.

50. Li HC, Cai J, Chen RJ, Zhao ZH, Ying ZK, Wang L, et al. Particulate matte exposure and stress hormone levels: A randomized, double-blind, crossover trial of air purification. Circulation. 2017; 136: 618-627.

51. Rajagopalan S, Brauer M, Bhatnagar A, et al. On behalf of the American Heart Association Council on Lifestyle and Cardiometabolic Health; Council on Arteriosclerosis, Thrombosis and Vascular Biology; Council on Clinical Cardiology; Council on Cardiovascular and Stroke Nursing; and Stroke Council. Personal-Level Protective Actions Against Particulate Matter Air Pollution Exposure: A Scientific Statement from the American Heart Association. Circulation. 2020; 142: e411-e431.

52. Lee S, Chang M. Indoor and outdoor air quality investigation at schools in Hong Kong. Chemosphere. 2000; 41: 109-113.

53. Rajagopalan S, Brook RD. Indoor-outdoor air pollution continuum and CVD burden - An opportunity for improving global health. Global Heart. 2012; 7 : 207-213

54. Samet JM, Bahrami $\mathrm{H}$ and Berhane $\mathrm{K}$. Indoor air pollution and cardiovascular disease: new evidence from Iran. Circulation. 2016; 133: 2342-2344. 